
Military Technical College Kobry El-Kobbah, Cairo, Egypt.

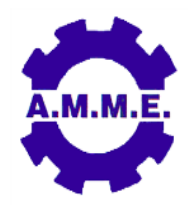

$17^{\text {th }}$ International Conference on Applied Mechanics and Mechanical Engineering.

\title{
DOUBLE SWASH PLATE PUMP WITH ADJUSTABLE VALVE RING CONCEPT
}

\author{
M. K. Bahr ${ }^{1}$
}

\begin{abstract}
Large size pumps have limited dynamics as compared to small pumps. The use of large size pumps is restricted by relatively low working pressure and low driving speed. A Large size pump has large bearing and frictional surfaces, so the increased working pressure reduces the service life of the pump.

A large size pump comprises large pistons, so with the high driving speed, a piston may detach from the piston shoes due to its inertia. The present invention is contrived to overcome the main limitation on the conventional design of swash plate pumps, particularly large size pumps. The present invention will benefit the swash plate pump designs of different style, fixed and variable displacement types, small and large size pumps.
\end{abstract}

The present invention is a double swash plate pump comprises a housing, doublesided cylinder block, two groups of pistons and, more particularly, an adjustable valve ring concept. Each group of pistons will be working simultaneously on one side of the same cylinder block.

1 Director and Professional Education and Research Development, Milwaukee School of Engineering, Milwaukee, WI, USA. 